\title{
Robotic simple prostatectomy: A consideration for large prostate adenomas
}

\author{
Joshua B. Nething ${ }^{1}$, Daniel J. Ricchiuti ${ }^{2}$, Rhys Irvine ${ }^{1}$, David Drevna ${ }^{1}$ \\ ${ }^{1}$ Northeastern Ohio Medical University Department of Urology, Akron, Ohio; \\ 2 St. Elizabeth Health Center, Division of Urology, Youngstown, Ohio.
}

\begin{abstract}
Summary Background: The management of benign prostatic hyperplasia (BPH) has changed considerably over the last several decades. First line treatment of BPH and lower urinary tract symptoms (LUTS) with medical therapy has created a population of men with much larger prostate glands, many of whom require surgical intervention. Patients with prostate glands greater than 80 to 100 grams may be better managed surgically with a retropubic prostatectomy. We explore our experience with robotic assisted simple prostatectomy and review the relevant literature. Database: The database reviewed includes our experience with seven patients undergoing robotic simple prostatectomy, and a comprehensive review of the previously published series of this procedure. In addition, the literature pertaining to a pure laparoscopic approach to simple prostatectomy is reviewed.

Conclusion: Robotic experience and training has become a standard in resident training programs; while classic transurethral resection is being performed less for large prostate glands. The robotic approach to simple prostatectomy provides an excellent option for surgical treatment of very large prostate glands, providing patients acceptable results in terms of operative time, estimated blood loss, hospital stay and duration of Foley catheter.
\end{abstract}

KEY WORDS: Robotics; Prostatectomy; Prostatic hyperplasia; Laparoscopy; Transurethral resection of prostate; Adenoma.

Submitted 5 May 2014; Accepted 31 May 2014

\begin{abstract}
INTRODUCTION
In the United States, more than $\$ 4$ billion is spent annually on the medical management (1) of Benign Prostatic Hyperplasia (BPH) and more than $\$ 2$ billion on the surgical management (2). Electrosurgical transurethral resection of the prostate (TURP) is the "gold-standard" for surgical treatment of BPH, growing in popularity since it was first described in 1911 by Hugh Young (3). The introduction of medications, the development for various lasers, the bipolar button and other novel technologies have all further decreased the number of TURPs being performed (4). The number of TURPs being performed
\end{abstract}

have gradually decreased from 229.2 to 268.3 per 100,000 men in 1980 through 1991 to 131.3 per 100,000 in 1994. In 2005 TURP represented 39\% of BPH procedures compared with 81\% in 1999 (4). As a result, graduating Urologists leaving residency training have performed fewer electrosurgical TURPs and the complication rate requiring a second procedure has increased (5). This lack of experience is exaggerated in very large glands as the potential for complications is expected to be higher. While Urologists who trained in the "golden age" of TURP are often confident approaching the largest adenomas transurethrally, less experience has led to reluctance to do so by younger Urologists. With the rapid increase in popularity of robotic surgical techniques, recent graduates are often more familiar with this minimally invasive technique to surgery. We present seven patients who underwent robotic assisted laparoscopic simple prostatectomy and a review of the contemporary literature on this subject.

\section{Patients and Methods}

Our experience consists of seven patients, all of which had failed multimodal medical treatment, with persistent bothersome LUTS leading to subsequent surgical intervention. Each patient underwent a successful robotic assisted laparoscopic simple prostatectomy without open conversion. The data that was collected through the course of our research is presented in Table 1.

Post-operative pathologic diagnosis on all specimens was prostatic hyperplasia. The Foley catheter was removed on the above-mentioned days (Table 1) after a cystogram was negative for leak. With an average follow-up time of 10 months, all patients were doing well with no noted longterm complications. No patients required further catheterization and all report overall improvement in their LUTS. A detailed report of the operative technique is described elsewhere in the literature (6). Briefly the key operative steps in this approach include dropping the bladder from the anterior abdominal fascia to enter the space of Retzius, then entering the bladder using a transverse incision $1 \mathrm{~cm}$ proximal to the bladder neck. A circumferential incision is made through the bladder mucosa and a plane is developed between prostate and capsule with combination of 
Table 1.

Data of patients.

\begin{tabular}{|l|c|c|c|c|c|c}
\hline Series & $\begin{array}{c}\text { Avg. OR } \\
\text { time } \\
\text { (mins) }\end{array}$ & $\begin{array}{c}\text { EBL } \\
\text { (ml) }\end{array}$ & $\begin{array}{c}\text { Foley } \\
\text { duration } \\
\text { (days) }\end{array}$ & $\begin{array}{c}\text { Hospital } \\
\text { stay } \\
\text { (days) }\end{array}$ & $\begin{array}{c}\text { Adenoma } \\
\text { size TRUS } \\
\text { (grams) }\end{array}$ & $\begin{array}{c}\text { Adenoma } \\
\text { size } \\
\text { (grams) }\end{array}$ \\
\hline Patient 1 & $188 \mathrm{~min}$ & $100 \mathrm{ml}$ & 7 days & 2 days & $187.04 \mathrm{~g}$. & $111 \mathrm{~g}$. \\
\hline Patient 2 & $175 \mathrm{~min}$ & $1200 \mathrm{ml}$ & 7 days & 2 days & $94.39 \mathrm{~g}$. & $125 \mathrm{~g}$. \\
\hline Patient 3 & $135 \mathrm{~min}$ & $300 \mathrm{ml}$ & 9 days & 2 days & $70 \mathrm{~g}$. & $71 \mathrm{~g}$. \\
\hline Patient 4 & $225 \mathrm{~min}$ & $200 \mathrm{ml}$ & 7 days & 2 days & $144 \mathrm{~g}$. & $56 \mathrm{~g}$. \\
\hline Patient 5 & $213 \mathrm{~min}$ & $400 \mathrm{ml}$ & 7 days & 2 days & $169 \mathrm{~g}$. & $86 \mathrm{~g}$. \\
\hline Patient 6 & $245 \mathrm{~min}$ & $50 \mathrm{ml}$ & 12 days & 7 days & $200 \mathrm{~g}$. & $123 \mathrm{~g}$. \\
\hline Patient 7 & $242 \mathrm{~min}$ & $1400 \mathrm{ml}$ & 9 days & 1 days & $150 \mathrm{~g}$. & $102 \mathrm{~g}$. \\
\hline Averages & $204.7 \mathrm{~min}$ & $521.4 \mathrm{ml}$ & 8.28 days & 2.57 days & $144.9 \mathrm{~g}$. & $96.3 \mathrm{~g}$. \\
\hline
\end{tabular}

and robotic approaches to this procedure have been explored. The initial reported case of laparoscopic simple prostatectomy was in 2002 by Mariano et al. (10).

The procedure was preformed in 225 minutes with an EBL of $800 \mathrm{ml}$ and the patient was discharge home in four days.

Mariano recently published his six year data, reviewing 60 patients, and demonstrated shorter hospital stay (3.46 days \pm 0.89 ), lower intraoperative blood loss $(330.98 \mathrm{ml} \pm 149.52)$ and more rapid removal of urinary catheter (4.6 days \pm 1.2 ) (11). Similar results have been published by several other authors, validating laparoscopic simple prostatectomy. Zhou et al. (12) used an extraperitoneal approach to laparoscopic adenomectomy. In their series of 45 patients, average surgical time was $105.4 \pm 26.5$ minutes, EBL was $360.1 \pm 165.4 \mathrm{ml}$, and average adenoma

blunt dissection and electrocautery. The prostate is than removed piecemeal at times and larger portions are morselated or removed using a reusable tissue retrieval bag. The mucosa of the bladder neck is tacked to the prostatic fossa using 2-0 Vicryl, and the bladder closed in 2 layers ensuring it is watertight.

\section{Discussion}

The 2003 AUA Guidelines recognize transurethral resection of prostate (TURP) as the benchmark for therapy of $\mathrm{BPH}$ as it permits a high success rate in symptom scores, urinary flow, post void residual and low retreatment rate on long term follow up (7).

This is a statement that the revised 2010 guidelines avoid making, further highlighting the decreased favorability of TURP. Multiple complications can be observed with TURP, including perioperative bleeding requiring blood transfusions, transurethral resection syndrome, prolonged catheterization, long hospital stay, urinary incontinence and retrograde ejaculation (4).

These drawbacks obviate the need for alternative treatment modalities, particularly with larger adenoma size, where the technical challenge and complication rate are magnified.

For patients with very large glands, typically defined as greater than 80 to $100 \mathrm{~mL}$, management options often include open simple prostatectomy (8). Open prostatectomy accounts for $14-32 \%$ of the total invasive procedures for $\mathrm{BPH}$ in Europe, and as many as 68\% in some developing countries (9). Traditional approaches for this procedure have been through an open incision, using a retropubic, suprapubic or perineal approach. Simple prostatectomy may be more effective than TURP at relieving obstruction of urinary flow, however it is usually associated with a larger blood loss, increased pain and longer hospital stay (8). In an effort to reduce these sequelae, laparoscopic
Table 2.

Published series for laparoscopic simple prostatectomy.

\begin{tabular}{|l|c|c|c|c|c|c|c|}
\hline Series & \# Pts. & $\begin{array}{c}\text { Avg. OR } \\
\text { time } \\
\text { (mins) }\end{array}$ & $\begin{array}{c}\text { EBL } \\
\text { (ml) }\end{array}$ & $\begin{array}{c}\text { Foley } \\
\text { duration } \\
\text { (days) }\end{array}$ & $\begin{array}{c}\text { Hospital } \\
\text { stay } \\
\text { (days) }\end{array}$ & $\begin{array}{c}\text { Adenoma } \\
\text { size TRUS } \\
\text { (grams) }\end{array}$ & $\begin{array}{c}\text { Adenoma } \\
\text { Size path } \\
\text { (grams) }\end{array}$ \\
\hline van Velthoven, 2004 & 18 & 145 & 192 & 3 & 5.9 & 95.1 & 47.6 \\
\hline Mariano, 2005 & 60 & 138.48 & 330.98 & 4.6 & 3.46 & 144.5 & 131 \\
\hline Sotelo, 2005 & 17 & 156 & 516 & 6.3 & 2 & 93 & 72 \\
\hline Baumert, 2006 & 30 & 115 & 367 & 4 & 5.1 & 121.8 & 77.2 \\
\hline Zhou, 2008 & 45 & 105.4 & 360.1 & 4.6 & 6.3 & 85.4 & 78.2 \\
\hline Yun, 2010 & 11 & 191.9 & 390.9 & 5.6 & 6.5 & 109.3 & 72.4 \\
\hline Castillo, 2011 & 59 & 123 & 415 & 4.2 & 3.5 & 108.5 & 95.2 \\
\hline
\end{tabular}


Table 3.

Published series of robotic simple prostatectomy.

\begin{tabular}{|l|c|c|c|c|c|c|c|}
\hline Series & \# Pts. & $\begin{array}{c}\text { Avg. OR } \\
\text { time } \\
\text { (mins) }\end{array}$ & $\begin{array}{c}\text { EBL } \\
\text { (ml) }\end{array}$ & $\begin{array}{c}\text { Foley } \\
\text { duration } \\
\text { (days) }\end{array}$ & $\begin{array}{c}\text { Hospital } \\
\text { stay } \\
\text { (days) }\end{array}$ & $\begin{array}{c}\text { Adenoma } \\
\text { size TRUS } \\
\text { (grams) }\end{array}$ & $\begin{array}{c}\text { Adenoma } \\
\text { size path } \\
\text { (grams) }\end{array}$ \\
\hline Sotelo, 2008 & 7 & 205 & 298 & 7 & 1.4 & 77.66 & 50.48 \\
\hline Yuh, 2008 & 3 & 211 & 558 & na & 1.3 & 323 & 301 \\
\hline John, 2009 & 13 & 210 & 500 & 6 & 6 & 100 & 82 \\
\hline Uffort, 2010 & 15 & 129 & 139 & 4.6 & 2.5 & 70.85 & 46.4 \\
\hline Coelho, 2011 & 6 & 90 & 208 & 4.8 & 1 & 157 & 145 \\
\hline This series & 5 & 187.2 & 440 & 7.4 & 1.8 & 132.89 & 89.8 \\
\hline
\end{tabular}

\section{Conclusion}

The 2010 AUA clinical guidelines cite longer catheter duration, greater EBL and longer hospital stay with the open prostatectomy, but continue to list this as a more effective treatment than TURP at relieving blockage of urine flow in men with very large glands (greater than 80 to $100 \mathrm{ml}$ ). As opposed to the theory that laparoscopic and robotic approaches are investigational, we believe that the advantage of a robotic approach is relevant and clearly defined by our experience and the referenced landmark papers discussed here.

Sotelo et al. (2008) (7) was the first to report their series of seven patients with robotic simple prostatectomy. He reported an EBL of $298 \mathrm{ml}$, average operative time of 205 minutes, average hospital stay of 1.4 days and Foley duration of 7 days. When comparing their findings to their previously reported series on laparoscopic simple prostatectomy, they concluded that robotics approach allows for greater precision and visualization with similar cost analysis (laparoscopic $\$ 10,465$ vs. $\$ 12,093$ for robotics).

Several recent publications on robotic simple prostatectomy showed similar results. Yuh et al. (21), in 2008, reported on a case series of three simple prostatectomies with average OR time of 211 minutes, EBL of $558 \mathrm{ml}$ and mean hospital stay of 1.3 days. Next, John et al. (22) reported their experience using an extraperitoneal approach.

The series consisted of 13 patients with average OR time of 210 minutes, EBL of $500 \mathrm{ml}$, adenoma weight of 82 grams, foley duration of 6 days and hospital stay of 6 days. In 2010, Uffort (23) series of 15 patients provided further evidence substantiating robotic simple prostatectomy as a valid treatment option.

Average operative time was 128.8 minutes, EBL was 139 $\mathrm{ml}$, average hospital time was 2.5 days and Foley duration was 4.6 days. Finally, Coelho et al. (24) further contribute to the published data in their series of six consecutive patients.

The Authors suggest a slightly modified procedure. Following resection of the adenoma, instead of performing the usual "trigonization" of the bladder neck, they proposed three modified steps as follows: placation of the posterior capsule, a modified van Velthoven continuous visco-urethral anastomosis and suturing of the anterior prostatic capsule to the anterior bladder wall. Detailed description of the procedure and illustrations can be referenced in the original publication. The authors reported a mean OR time of 90 minutes, EBL $208 \mathrm{ml}$, hospital stay of 1 day and Foley duration was 4.8 days.

The Authors suggest that technical modification offers the potential advantage of decreased blood loss, no need for postoperative continuous bladder irrigation, and shorter length of hospital stay. A complete review of the written literature, included our experience of robotic simple prostatectomy is summarized in Table 3.
Robotic surgery offers an obvious advantage to traditional laparoscopy in regards to visual enhancement, and wristed movements allowing for increased dexterity.

The robotic approach allows for a shorter learning curve to a complex case.

This article should highlight the excellent patient outcomes achievable with laparoscopic simple prostatectomy, and one that is feasible with most contemporary urologists comfort and skill for robotic surgical assistance.

\section{REFERENCES}

1. Holtgrewe HL, Ackermann R, Bay-Nielsen H, et al. Report from the Committee on the Economics of BPH. In: Cockett ATK et al., eds. Third international consultation on benign prostatic hyperplasia (BPH). Jersey: Scientific Communication International. 1996; 51-70.

2. McConnell JD, Barry MJ, Bruskewitz RC, et al. Benign Prostatic Hyperplasia: Diagnosis and treatment. Clinical Practice Guidelines No. 8. AHCPR publication No. 94- 0582. Rockville, Maryland: Agency for Health Care Policy and Research. Public Health Service, US Dept of Health and Human Services, 1994.

3. Ellis $H$. The early days of prostatectomy for benign prostatic hypertrophy. J Perioper Pract. 2011; 10:359.

4. Rocco B, Albo G, Ferrreira R, et al. Recent advances in the surgical treatment of benign prostatic hyperplasia. Ther Adv Urol. 2011; 3:263-272.

5. Sandhu J, Jaffe W, Chung D, et al. Decreasing Electrosurgical Transurethral Resection of the Prostate Surgical Volume During Graduate Medical Education Training is Associated with Increased Surgical Adverse Events. J Urol. 2010; 183:1515-1519.

6. Sotelo R, Clavijo R, Carmona O, et al. Robotic Simple Prostatectomy. J Urol. 2008; 179:513-515.

7. American Urologic Association. Guidelines for management of BPH, 2003. Available at: http://www.auanet.org/content/clinicalpractice-guidelines/clinical-guidelines/archived-guidelines/chapt_ 1_appendix.pdf. Accessed February 24, 2012.

8. American Urologic Association. Management of BPH (Revised, 2010). Available at: http://www.auanet.org/content/clinical-practice-guidelines/clinical-guidelines.cfm. Accessed February 24, 2012.

9. Vela Navarette R, Gonzales Enquita C, Garcia Cardoso, et al. The impact of medical therapy on surgery for benign prostatic hyperplasia: a study comparing changes in a decade. BJU Int. 2005; 96:1045-1048. 
10. Mariano MB, Graziottin TM, Tefilli MV. Laparoscopic Prostatectomy with vascular control for benign prostatic hyperplasia. J Urol. 2002; 167:2528-2529.

11. Mariano MB, Tefilli MV, Graziottin TM, et al. Laparoscopic Prostatectomy for Benign Prostic Hyperplasia- A Six Year Experience. Eur Urol. 2006; 49:127-132.

12. Zhou LY, Xiao J, Chen H, et al. Extraperitoneal laparoscopic adenomectomy for benign prostatic hyperplasia. Worl J Urol. 2009; 27:385-387.

13. Yun HK, Kwon JB, Cho SR, et al. Early Experience with Laparoscopic Retropubic Sumple Prostatectomy in Patients with Voluminous Benign Prostatic Hyperplasia (BPH). Korean J Urol. 2010; 51:323-329.

14. Baumert H, Ballaro A, Dugardin F, et al. Laparoscopic Versus Open Simple Prostatectomy. J Urol. 2006; 175:1691-1694.

15. Sotelo R, Spaliviero M, Garcia Sequi A, et al. Laparoscopic Reteropubic Simple Prostatectomy. J Urol. 2005; 173:757-760.

16. Castillo OA, Bolufer E, Lopez- Fontana G, et al. Laparoscopic simple prostatectomy (adenomectomy): Experience in 59 consecutive patients. Actas Urol Esp. 2011; 35:433-437.

17. Van Velthoven R, Peltier A, Laguna MP, et al. Laparoscopic
Extraperitoneal Adenomectomy (Millin): Pilot study on feasibility. Eur Urol. 2004; 45:103-109.

18. Desai M, Aron M, Canes D, et al. Single Port Transvesical Simple Prostatectomy: Initial Clinical Report. Urology. 2008; 72:960-965.

19. Yohonnes P, Rotariu P, Pinto et al. Comparison of robotic versus laparoscopic skills: is there a difference in the learning curve? Urology. 2002; 60:39-45.

20. Sarle R, Tewari A, Shrivastava A, et al. Surgical robotics and laparoscopic training drills. J Endourol. 2004; 18:63-67.

21. Yuh B, Laungani R, et al. Robotic Assisted Millins Retropubic prostatectomy: case series. Can J Urol. 2008; 15:4101-4105.

22. John H, Bucher C, Engel N, et al. Preperitoneal Robotic Prostate Adenomectomy. Urology. 2009; 73:811-815.

23. Uffort E, Jensen J. Robotic assisted laparoscopic simple prostatectomy: an alternative minimally invasive approach for prostate adenoma. J Robotic Surg. 2010; 4:7-10.

24. Coelho R, Chauhan S, Sivaraman A, et al. Modified technique of robotic assisted simple prostatectomy: advantages of a vesico-urethral anastomosis. BJU Int. 2012; 109:426-433.

\section{Correspondence}

Joshua B. Nething, MD

jnething@gmail.com

Rhys Irvine, MD (Corresponding Author)

rwirvine@gmail.com

Dave Drevna

ddrevna@neomed.edu

Northeastern Ohio Medical University Department of Urology

215 West Bowery Street, Suite 3500, Akron, Ohio 44308

Daniel J. Ricchiuti, MD

dricchiuti@yahoo.com

St Elizabeth Health Center, Division of Urology

1044 Belmont Avenue, Youngstown, Ohio 44501 